\section{Case Reports in Ophthalmology}

Case Rep Ophthalmol 2020;11:523-527

This article is licensed under the Creative Commons Attribution-NonCommercial 4.0 International License (CC BY-NC) (http://www.karger.com/Services/OpenAccessLicense). Usage and distribution for commercial purposes requires written permission.

\title{
Bilateral Exudative Retinal Detachments Associated with Nivolumab Immunotherapy
}

\author{
Radwan S. Ajlan Joey Luvisi Connor Brass \\ Department of Ophthalmology, University of Kansas School of Medicine, Kansas \\ City, KS, USA
}

\section{Keywords}

Nivolumab immunotherapy · Exudative retinal detachment · Immune checkpoint inhibitors

\begin{abstract}
A 58-year-old Caucasian female presented to the retina service with a 2-week history of bilateral decrease in vision. She had stage 4 renal cell carcinoma with osseous metastasis and choroidal metastasis for which she has been treated with Nivolumab immunotherapy. Her exudative retinal detachments resolved after cessation of Nivolumab in association with subtenon steroids (STK) and intravitreal bevacizumab injections. To the best of our knowledge, this is the first report in the literature describing the resolution of Nivolumab-related exudative retinal detachment after early local therapy using STK injections $(10 \mathrm{mg})$, bevacizumab intravitreal injections, and cessation of Nivolumab. We hope by sharing this report to provide new insight into the management of similar patients.

(C) 2020 The Author(s)

Published by S. Karger AG, Basel
\end{abstract}

\section{Introduction}

Immune therapy had a major role in treating malignancies, including renal cell carcinoma. However, immune checkpoint inhibitors made a pivotal change in the use of the immune system against cancer cells. Nivolumab is a fully human immunoglobulin antibody that acts as a checkpoint inhibitor [1]. It inhibits programmed cell death protein 1 ligand expressed by 


\section{Case Reports in Ophthalmology}

Case Rep Ophthalmol 2020;11:523-527 DOI: 10.1159/000508091

(c) 2020 The Author(s). Published by S. Karger AG, Basel www.karger.com/cop

Ajlan et al.: Nivolumab-Associated Exudative Retinal Detachment

tumor cells and by infiltrating immune cells [2]. Nivolumab is generally tolerated, with reported ophthalmic immune-related alternative effects including uveitis, ulcerative keratitis, and Vogt-Koyanagi-Harada-like symptoms [3, 4]. To the best of our knowledge, this is the first reported case in the literature of bilateral exudative retinal detachment associated with nivolumab as the sole checkpoint inhibitor. In addition, this is the first report of a patient treated with nivolumab cessation in combination with local steroids and bevacizumab injections.

\section{Case Presentation}

A 58-year-old Caucasian female presented to the retina service with a 2-week history of bilateral decrease in vision. Her past medical history was significant for stage 4 renal cell carcinoma with osseous metastasis, for which she has been treated with Nivolumab for 2 years (38 doses of $240 \mathrm{mg}$ completed) and Denosumab for 4-years (27 cycles of $120 \mathrm{mg}$ completed). Her past ocular history was significant for mild cataracts and bilateral posterior vitreous detachments noted 3 years before.

On clinical examination, her visual acuity was OD 20/60 and OS 20/80, with intraocular pressure of $10 \mathrm{~mm} \mathrm{Hg} \mathrm{OU}$. Anterior segment examination was significant for 1+ nuclear sclerotic cataracts OU. Fundus examination revealed bilateral choroidal metastasis with exudative retinal detachments (Fig. 1). It was unclear at this time if the exudative retinal detachments were a side effect of Nivolumab therapy or choroidal metastasis-related vascular endothelial growth factors (VEGFs). The patient received intravitreal bevacizumab $1.25 \mathrm{mg} / 0.5 \mathrm{~mL}$ OS to counteract potential choroidal metastasis VEGFs. Two weeks later, the patient presented with a further decrease in vision and bilateral increase in subretinal fluid (OD: 20/80, OS: 20/125) (Fig. 2a). At that point, the decision to hold on Nivolumab was reached after discussion with the treating oncologist. Subtenon triamcinolone acetonide (STK) $10 \mathrm{mg}$ was provided to enhance visual recovery in the left eye. One month later, the patient reported subjective improvement in her vision OS, with a bilateral decrease in the subretinal fluid on optical coherence tomography scans (OD < OS). STK was provided to the right eye, as per patient's request, to enhance visual recovery after confirming she was not a steroid responder.

On follow-up with the oncology team, the patient had cancer progression after discontinuing her Nivolumab and was started on Cabozantinib $20 \mathrm{mg} /$ daily. The choroidal lesions continued to enlarge; as a result, an anti-VEGF agent was incorporated to counteract any VEGFs secreted by the choroidal metastases. The patient had two additional STK injections OD at 2month intervals, and two intravitreal bevacizumab injections OU in between her STK injections. Her subretinal fluid continued to resorb, and her cataracts progressed (OD: 20/700, OS: 20/500).

At that point, the patient was referred to the cornea team for cataract extraction and posterior chamber lens implants in the right eye, which was followed by the left eye 1 month later. After 1 year from the initial presentation, the final visual acuity was OD 20/80 and OS 20/50 with attached retina. STK was continued as needed for recurrent subretinal fluid and macular edema. (Fig. 2b). 


\section{Case Reports in Ophthalmology}

\section{Discussion}

Over the last decade, there have been rapid developments in immunomodulation therapy for different malignancies. Checkpoint inhibitors have been tolerated with a wide array of systemic side effects including fatigue (26-53\%), skin rash (1-50\%), lymphocytopenia (1049\%), and increased liver function tests (1-46\%) [3-7]. Mantopoulos et al. [6] reported a case of bilateral choroidopathy and serous retinal detachments in a patient on checkpoint inhibitors (ipilimumab). Initial management included ipilimumab cessation, topical steroids, and was followed by systemic steroids 1 month later. Kim et al. [3] reported bilateral exudative retinal detachment in a patient on Nivolumab and Ipilimumab. The patient was managed by local and systemic steroids, in addition to the cessation of Nivolumab therapy. The final visual acuity was counting fingers and 20/400, with persistent bilateral chronic serous retinal detachments.

Systemic steroids can be useful in treating patients with immunotherapy side effects and may extend the duration of the immunotherapy course. However, systemic steroids have side effects of their own that need to be monitored, for example, dermatological (fragile skin, mild hirsutism), musculoskeletal (osteoporosis), behavioral (mood swings, euphoria, depression), and gastrointestinal (peptic ulcer) side effects [8]. The patient in this report had right arm amputation, metastatic disease, feet ulcers, and a 200-mile commute to and from the clinic; however, she said that she would rather not be alive if she cannot see. To avoid systemic steroid side effects, the patient was started on local ocular steroids with the option of systemic steroids postponed as needed.

In this unique case, additional factors may have contributed to serous retinal detachment formation besides Nivolumab therapy, such as the choroidal metastases' neovascular activity. Choroidal neovascularization was reported as a side effect with other checkpoint inhibitors (Ipilimumab) [9], and intravitreal bevacizumab decreased the nonvascular activity of metastatic choroidal metastases and tumors [10]. For these reasons, bevacizumab was started and was continued throughout the treatment course when an augmented anti-VEGF effect was needed.

\section{Conclusion}

To the best of our knowledge, this is the first report in the literature that showed the resolution of Nivolumab-related exudative retinal detachment with a combination of early local therapy using STK injections (10 mg), bevacizumab intravitreal injections, and cessation of Nivolumab. The personalized, multidisciplinary team approach played an important role in improving the patient's visual outcome and quality of life while allowing her to avoid systemic steroids. We hope by sharing this report to provide new insight into the management of similar patients.

\section{Statement of Ethics}

The patient provided her informed consent to publish her case (including publication of images). 


\section{Case Reports in Ophthalmology}

\begin{tabular}{l|l}
\hline DOI: $10.1159 / 000508091$ & (c) 2020 The Author(s). Published by S. Karger AG, Basel
\end{tabular}
www.karger.com/cop

Ajlan et al.: Nivolumab-Associated Exudative Retinal Detachment

\section{Disclosure Statement}

The authors have no financial conflicts or conflicts of interest to disclose.

\section{Funding Sources}

No funding support was provided for this case report.

\section{Author Contributions}

R.A.: draft and revision of the manuscript, review of the literature, and image editing. J.L.: manuscript editing, review of the literature, and image editing. C.B.: manuscript editing. All authors have approved the final version of the manuscript.

\section{References}

1 Guo L, Zhang H, Chen B. Nivolumab as Programmed Death-1 (PD-1) Inhibitor for Targeted Immunotherapy in Tumor. J Cancer. 2017 Feb;8(3):410-6.

2 Mazza C, Escudier B, Albiges L. Nivolumab in renal cell carcinoma: latest evidence and clinical potential. Ther Adv Med Oncol. 2017 Mar;9(3):171-81.

3 Kim JM, Materin MA, Sznol M, Kluger HM, Weiss S, Chow J, et al. Ophthalmic Immune-Related Adverse Events of Immunotherapy: A Single-Site Case Series. Ophthalmology. 2019 Jul;126(7):1058-62.

4 Theillac C, Straub M, Breton AL, Thomas L, Dalle S. Bilateral uveitis and macular edema induced by Nivolumab: a case report. BMC Ophthalmol. 2017 Dec;17(1):227.

5 Dalvin LA, Shields CL, Orloff M, Sato T, Shields JA. Checkpoint Inhibitor Immune Therapy: Systemic Indications and Ophthalmic Side Effects. Retina. 2018 Jun;38(6):1063-78.

6 Mantopoulos D, Kendra KL, Letson AD, Cebulla CM. Bilateral Choroidopathy and Serous Retinal Detachments During Ipilimumab Treatment for Cutaneous Melanoma. JAMA Ophthalmol. 2015 Aug;133(8):965-7.

7 Crews J, Agarwal A, Jack L, Xu D, Do DV, Nguyen QD. Ipilimumab - Associated Retinopathy. Ophthalmic Surg Lasers Imaging Retina. 2015;46(6):658-60.

8 Stanbury RM, Graham EM. Systemic corticosteroid therapy—side effects and their management. Br J Ophthalmol. 1998 Jun;82(6):704-8.

9 Antoun J, Titah C, Cochereau I. Ocular and orbital side-effects of checkpoint inhibitors: a review article. Curr Opin Oncol. 2016 Jul;28(4):288-94.

10 Cohen VM. Ocular metastases. Eye (Lond). 2013 Feb;27(2):137-41. 
Case Reports in Ophthalmology
Case Rep Ophthalmol 2020;11:523-527

DOI: 10.1159/000508091

(c) 2020 The Author(s). Published by S. Karger AG, Basel www.karger.com/cop

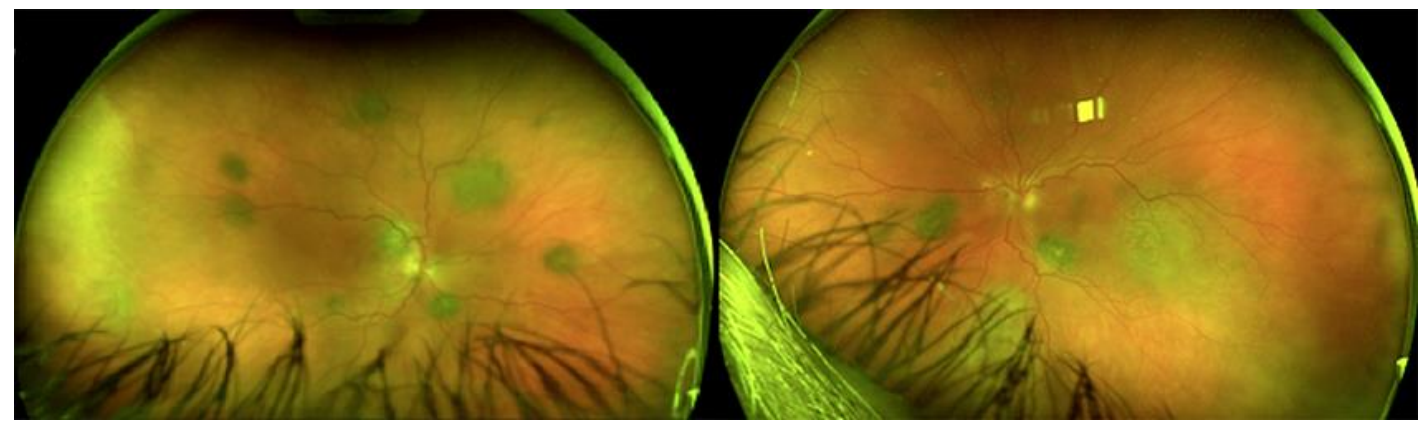

Fig. 1. Ultrawide field fundus photos demonstrating choroidal metastasis.
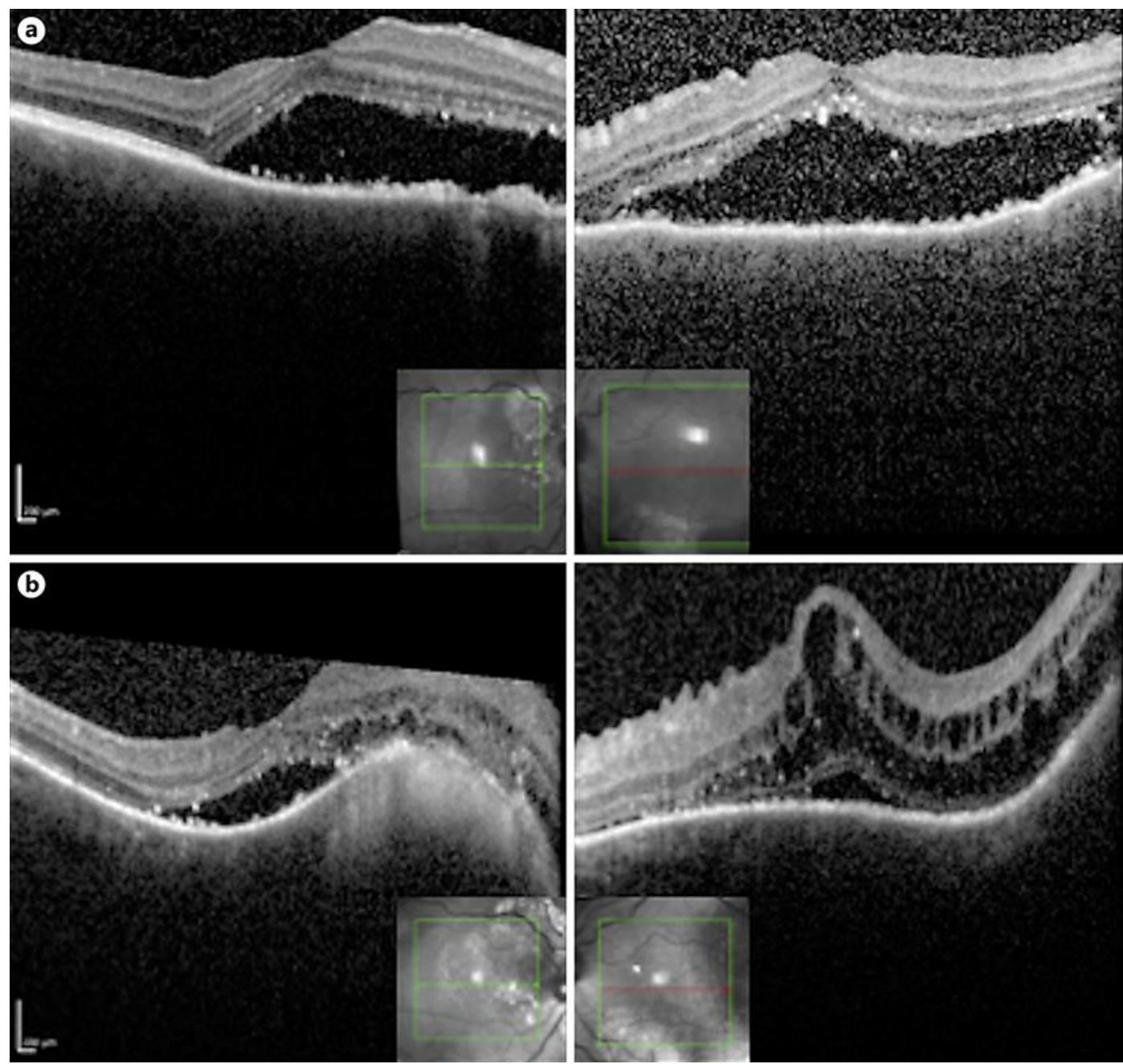

Fig. 2. Spectral-domain optical coherence tomography scans demonstrating exudative retinal detachment on presentation in the top images (a). Significant decrease in the subretinal fluid with residual subfoveal fluid pockets and macular edema (b). 